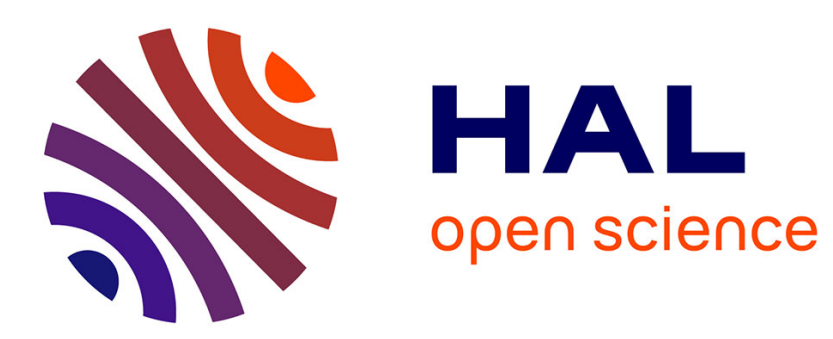

\title{
Planar Microcoil OptimPlanar Microcoil Optimization of MEMS Electrodynamic Microspeakers
}

I Shahosseini, E Lefeuvre, J Moulin, E Martinicic, M Woytasik, Gaël Pillonnet, G Lemarquand

\section{- To cite this version:}

I Shahosseini, E Lefeuvre, J Moulin, E Martinicic, M Woytasik, et al.. Planar Microcoil OptimPlanar Microcoil Optimization of MEMS Electrodynamic Microspeakers. IEEE Transactions on Magnetics, 2013, pp.8. 10.1109/TMAG.2013.2246180 . hal-01103602

\section{HAL Id: hal-01103602 \\ https://hal.science/hal-01103602}

Submitted on 15 Jan 2015

HAL is a multi-disciplinary open access archive for the deposit and dissemination of scientific research documents, whether they are published or not. The documents may come from teaching and research institutions in France or abroad, or from public or private research centers.
L'archive ouverte pluridisciplinaire HAL, est destinée au dépôt et à la diffusion de documents scientifiques de niveau recherche, publiés ou non, émanant des établissements d'enseignement et de recherche français ou étrangers, des laboratoires publics ou privés. 


\section{Planar Microcoil Optimization of MEMS Electrodynamic Microspeakers}

\begin{tabular}{|r|l|}
\hline Journal: & IEEE Transactions on Magnetics \\
\hline Manuscript ID: & Draft \\
\hline Article Type: & 1 Paper \\
\hline Date Submitted by the Author: & n/a \\
\hline Complete List of Authors: & $\begin{array}{l}\text { Shahosseini, Iman; University of Paris Sud, } \\
\text { Lefeuvre, Elie; University of Paris Sud, } \\
\text { Moulin, Johan; University of Paris Sud, } \\
\text { Martinicic, Emile; University of Paris Sud, } \\
\text { Woytasik, Marion; University of Paris Sud, } \\
\text { Pillonnet, Gael; Institut des Nanotechnologies de Lyon, } \\
\text { Lemarquand, Guy; Laboratoire d'Acoustique de I'Université du Maine, }\end{array}$ \\
\hline Keywords: & \begin{tabular}{l} 
Efficiency, Electrodynamic, Magnet, MEMS, Microspeaker, Planar coil \\
\hline
\end{tabular} \\
\hline
\end{tabular}




\title{
Planar Microcoil Optimization of MEMS Electrodynamic Microspeakers
}

\author{
I. Shahosseini ${ }^{1}$, E. Lefeuvre ${ }^{1}$, J. Moulin ${ }^{1}$, E. Martinicic ${ }^{1}$, M. Woytasik ${ }^{1}$, G. Pillonnet ${ }^{2}$, G. Lemarquand $^{3}$ \\ ${ }^{1}$ Institut d'Electronique Fondamentale, Univ. Paris Sud / CNRS, 91405 Orsay, France \\ ${ }^{2}$ Institut des Nanotechnologies de Lyon (INL) - UMR CNRS 5270, Lyon, France \\ ${ }^{3}$ Laboratoire d'Acoustique de l'Université du Maine, Université du Maine / CNRS, 72085 Le Mans, France
}

\begin{abstract}
A method for optimizing the planar microcoil of MEMS electrodynamic microspeakers with the aim of maximizing the electroacoustic efficiency is presented. The poposed approach is based on a mixed-model using both analytical models and finite element method (FEM). FEM simulation was used for computing the spatial distribution of the magnetic field created by the permanent magnets, making thus possible to analyze any geometry of permanent magnets. Different configurations of magnets were considered, and for each the planar copper microcoil was optimized while taking into account the technological constraints due to the microfabrication process, the associated electronics and the targeted acoustic power emission. The results showed that the proposed method predicts the force factor in very good agreement with experimental measurements carried out on the micromachined device. Morover, according to the electro-mechano-acoustic model, these results showed that the optimized microcoil associated to the best magnet configuration increases the electroacoustic efficiency by more than $200 \%$ compared to conventional microspeakers.
\end{abstract}

Index Terms—Efficiency, Electrodynamic, Magnet, MEMS, Microspeaker, Planar coil

\section{INTRODUCTION}

$\mathrm{T}$ oday, microspeakers are embedded in numerous electronic mobile devices such as cellular phones, notebooks, cameras, camcorders and small video-game devices. The increasing complexity and number of functions of mobile devices induces a strong increase of their power consumption. Progresses achieved on batteries have unfortunately not followed the same rhythm. Consequently, the poor autonomy of mobile devices is becoming a real problem.

In the case of mobiles phones, almost a quarter of the battery energy is consumed by the audio system [1]. The analysis of each element of the sound generation system reveals that the microspeaker is the efficiency bottleneck. Indeed, typical efficiency of conventional microspeakers is far below $0.1 \%$ [2], whereas overall efficiency of the associated electronics (filters, amplifiers) are usually situated above $50 \%$ [3], [4].

Today's microspeakers are manufactured by employing conventional technologies, which have low dimensional precision and propose a limited choice of materials. For instance, polymers like poly ethylene naphthalene (PEN) or polyacrylate compound are the typical materials used for the diaphragm of conventional microspeakers [5], [6], [7]. Compared to materials as monocrystalline silicon, which can be easily machined by Microelectromechanical systems (MEMS) technologies, such polymer materials present undesirable mechanical behavior. Indeed, the existence of many mechanical proper modes of the diaphragm in the audible frequency band degrades the sound quality of the transducer [8]. Another major advantage of MEMS technologies is the high dimensional precision, below one micron, unachievable by conventional technologies. These aspects help to conceive and fabricate high performance

Manuscript received October 19, 2012. Corresponding author: I. Shahosseini (e-mail: iman.shahosseini@u-psud.fr).

Digital Object Identifier inserted by IEEE electromechanical transducers.

With the aim of improving the energy autonomy of mobile devices, this work studies the electromagnetic structure of a silicon-based microspeaker, and more specifically the planar voice coil. For this purpose, an optimization method based on a mixed-model is presented. This model couples analytical equations and Finite Element Method (FEM). In the proposed approach, the use of FEM is restricted to computation of the magnetic field created by the permanent magnets. This is particularly interesting in case of magnetic structures for which analytical methods are difficult to implement.

In several previous works related to electrodynamic microspeakers, studies of the electromagnetic motor were reported, but, to our knowledge, the optimization of the voice coil was never clearly stated. They used either analytical or FEM models to analyze the flux pattern of the designed electromagnetic actuation [9], [10], [11], [12]. Some works reported the resulted driving force through computing the components of the magnetic field contributing to actuation [5], [13], [14]. However, the optimization of the voice coil dimensions was not presented. Few works, nevertheless, studied the magnetic field as a function of the coil in-plane or out-of-plane displacement to optimize the voice coil position [15], [16], [17]. Je et al. [18] reported the diaphragm displacement obtained for different coil configurations, without seeking the optimum coil geometry.

The study presented herein aims at optimizing the planar voice coil of a MEMS microspeaker to maximize its electroacoustic efficiency. This paper is organized as follows: first, the architecture of the MEMS microspeaker is presented in section II. Then, in section III, two different configurations of permanent magnets are examined in terms of spatial distribution of the magnetic flux density. The optimization method of the planar microcoil is then presented in section IV. Theoretical predictions are finally compared to the experimental measurements in section $\mathrm{V}$, before the 
conclusion.

\section{StRUCTURE OF THE MICROSPEAKER}

The structure of the considered MEMS microspeaker is depicted in Fig. 1. It is composed of a circular silicon membrane suspended to the substrate by a set of silicon springs. A planar microcoil is located on top of the silicon membrane. The electrical contact is achieved by two copper conductor tracks located on top of two of the suspension springs. These elements and the silicon membrane define the mobile part of the microspeaker. The magnetic field is created by either one or two ring-shaped permanent magnets, bonded respectively on top side or on both sides of the silicon substrate. The spacer represented in Fig. 1 is used to adjust the magnet-membrane distance.

What differs this structure from conventional microspeakers is the absence of soft magnetic materials to confine the magnetic field. Indeed, despite some works reported the integration of such materials [18], this complicates significantly the device microfabrication. Moreover, the presence of soft magnetic materials introduce additional nonlinearities in the electroacoustic response [19].

As mentioned in previous works of the authors, thanks to the mechanical properties of silicon single-crystal and the optimized stiffening microstructure on the backside of the membrane, the mobile part remains light and rigid [20]. These parameters strongly influence the sound quality and the efficiency of the transducer. Silicon material was also used for the suspension springs due to outstanding linearity of its mechanical properties and very long fatigue life [21], [22]. These are necessary factors to get a high quality of sound reproduction in audio systems.

With the presented structure, thanks to the high rigidity of the membrane, the sound waves are generated by piston-like movement. Such working mode is more beneficial for the sound quality comparing to other acoustic emission principles based on flexible diaphragms, whose proper modes degrade the sound quality [18], [23]. As detailed in [24], to generate 80 $\mathrm{dB}$ sound pressure level (SPL) in $10 \mathrm{~cm}$ distance of the microspeaker for the frequency bandwidth of $300 \mathrm{~Hz}$ to 20 $\mathrm{kHz}$, which corresponds to mobile phones application, an outof-plane displacement up to $\pm 300 \mu \mathrm{m}$ is required for a $15 \mathrm{~mm}$ in diameter membrane.

To supply such displacement, the electromagnetic motor should generate the force in need. The driving force $F_{Z}$, which is the component of the Lorentz force along $z$ axis (Fig. 2), results from the interaction between the microcoil and the magnetic field. It can be calculated by (1) in the case of a circular planar microcoil [25]:

$$
F_{z}=\sum_{i=1}^{N} I \cdot 2 \pi \cdot R_{i} \cdot B_{r(i)}=F_{f} \cdot I
$$

Where $I$ is the electric current injected into the microcoil consisting of $N$ turns, $R_{i}$ the radius of each coil turn, and $B_{r(i)}$ the radial component of the magnetic field nearby each coil turn. This relation can be also described as the product of the electric current $I$ through the coil and the force factor $F_{f}$ which is an intrinsic characteristic of the coil-magnet structure.

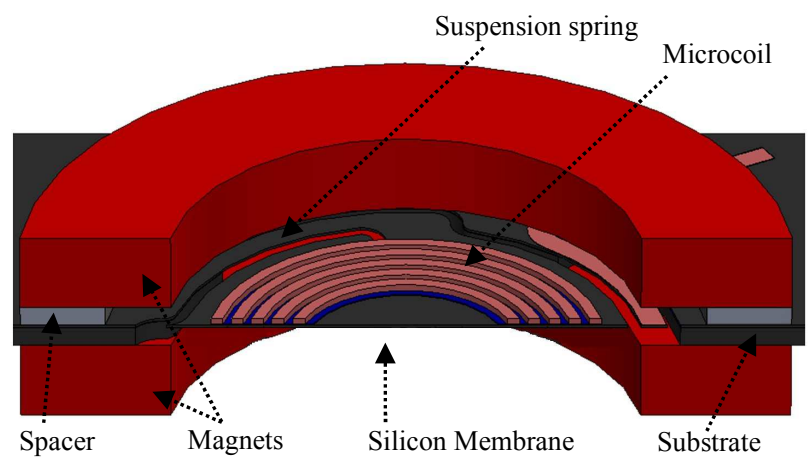

Figure 1) Cut view of the MEMS electrodynamic microspeaker with two-ring magnets

The force factor should be as high as possible to minimize the needed electric current. According to (1), this can be achieved by deploying as long as possible voice-coil and a magnetic structure providing strong $B_{r}$. However, as it will be detailed in the following sections, the voice coil mass is another parameter to consider because of its adverse effect on the microspeaker efficiency.

\section{RADIAL MAGNETIC FLUX DENSITY}

The magnetic flux density created by two different structures of permanent magnets is analyzed here. As shown in Fig. 2-a, the first structure uses one ring magnet located in front side of the device, making a vertical distance of $300 \mu \mathrm{m}$ from the coil plane in the rest position. As discussed in part II, this corresponds to the membrane displacement when the microspeaker undergoes the extreme working conditions. The cut view of Fig 2-b depicts the second structure, composed of two ring magnets. The topside magnet remains at $300 \mu \mathrm{m}$ distance from the coil plane, and the bottom side magnet is positioned in $600 \mu \mathrm{m}$ distance from the membrane plane, in order to enable $\pm 300 \mu \mathrm{m}$ out-of-plane displacement of the 300 $\mu \mathrm{m}$ thick membrane. For each configuration, an axial magnetization field in the $z$-axis direction was considered for the magnets.

The radial magnetic flux density was calculated in each case using FEM. For this purpose, the axisymmetric geometry of the 3D structure enabled to use 2D models for FEM simulations. The ring magnets were simulated considering a magnetization field of $1.5 \mathrm{~T}$, an inner diameter of $16 \mathrm{~mm}$, an outer diameter of $22 \mathrm{~mm}$, and a thickness of $3 \mathrm{~mm}$. These specifications correspond to available $\mathrm{NdFeB}$ bulk magnetic material. 


\section{Page 3 of 7}

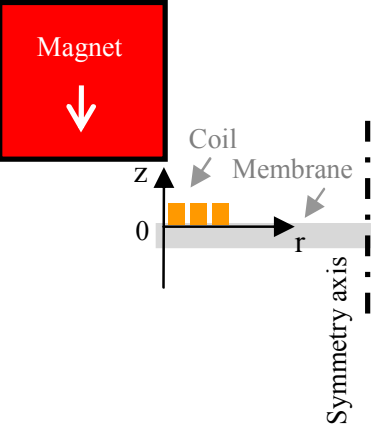

(a)

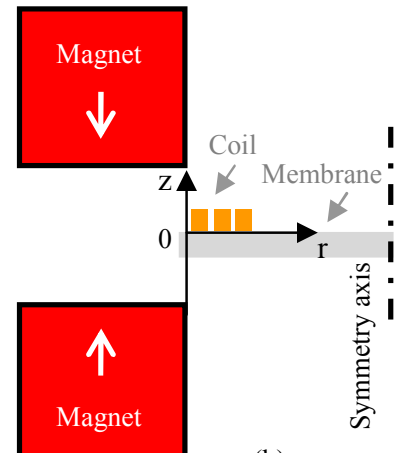

(b)

Figure 2) Cut view of magnetic structures: (a) one ring magnet in $300 \mu \mathrm{m}$ distance from the coil plane rest position, (b) two ring magnets respectively in $300 \mu \mathrm{m}$ and $600 \mu \mathrm{m}$ distances from front side and backside

Fig. 3 shows the magnetic field near the magnets obtained by FEM using ANSYS software. It can be seen that for the two-ring configuration, the magnetic field lines are concentrated between the two ring magnets (Fig. 3-b vs. Fig. $3-a)$. The radial component of magnetic flux density, being the only component contributing to displacement along the z-axis, was calculated for each point in the zone of the microcoil possible positions. Fig. 4-a and Fig. 4-b show the values of $B_{r}$ as a function of the vertical distance $z$ and for several $r$ distances from the origin " 0 " defined in Fig 2. The $z$-axis graded from $-300 \mu \mathrm{m}$ up to $+300 \mu \mathrm{m}$ represents the microcoil out-of-plane displacement range. The $r$ distance from the magnets inner edge was considered between 0.2 and $4.0 \mathrm{~mm}$.

(a)

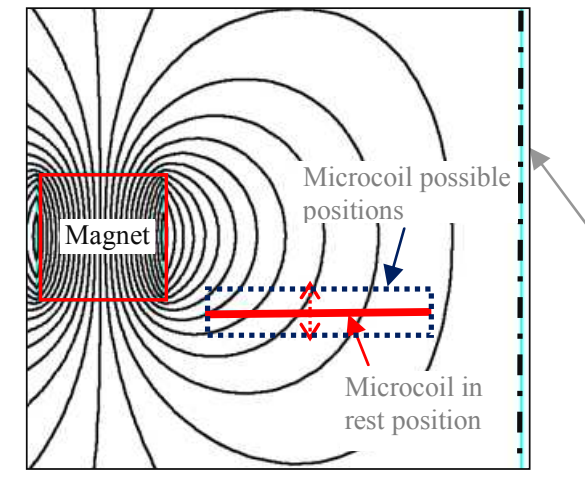

(b)

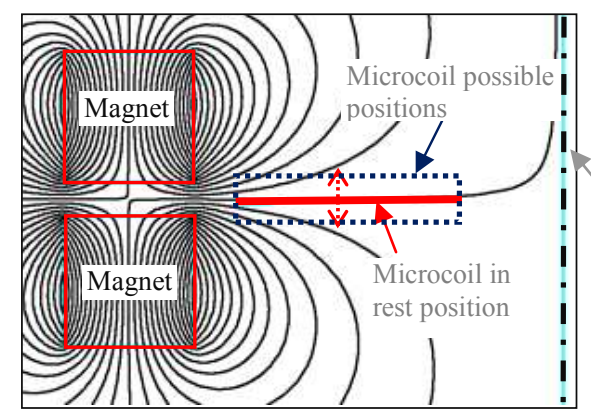

Figure 3) Spatial distribution of magnetic field: (a) one magnet with axial magnetization, (b) two magnets with axial magnetization

It should be mentioned that for any $r$ distance, less variation in $B_{r}$ following the $z$-axis means less variations of the force factor along the microcoil displacement. In addition, according to (1), the higher the $B_{r}$ is, the bigger the force factor will be.
The former characteristic contributes to improve the linearity of the electromechanical conversion, and the latter provides higher actuation effectiveness. According to FEM simulation results, the configuration of two ring magnets produces stronger and more homogenous radial component of the magnetic flux density. These phenomena are even more significant for small $r$ distances (Fig 4-b vs. Fig. 4-a).
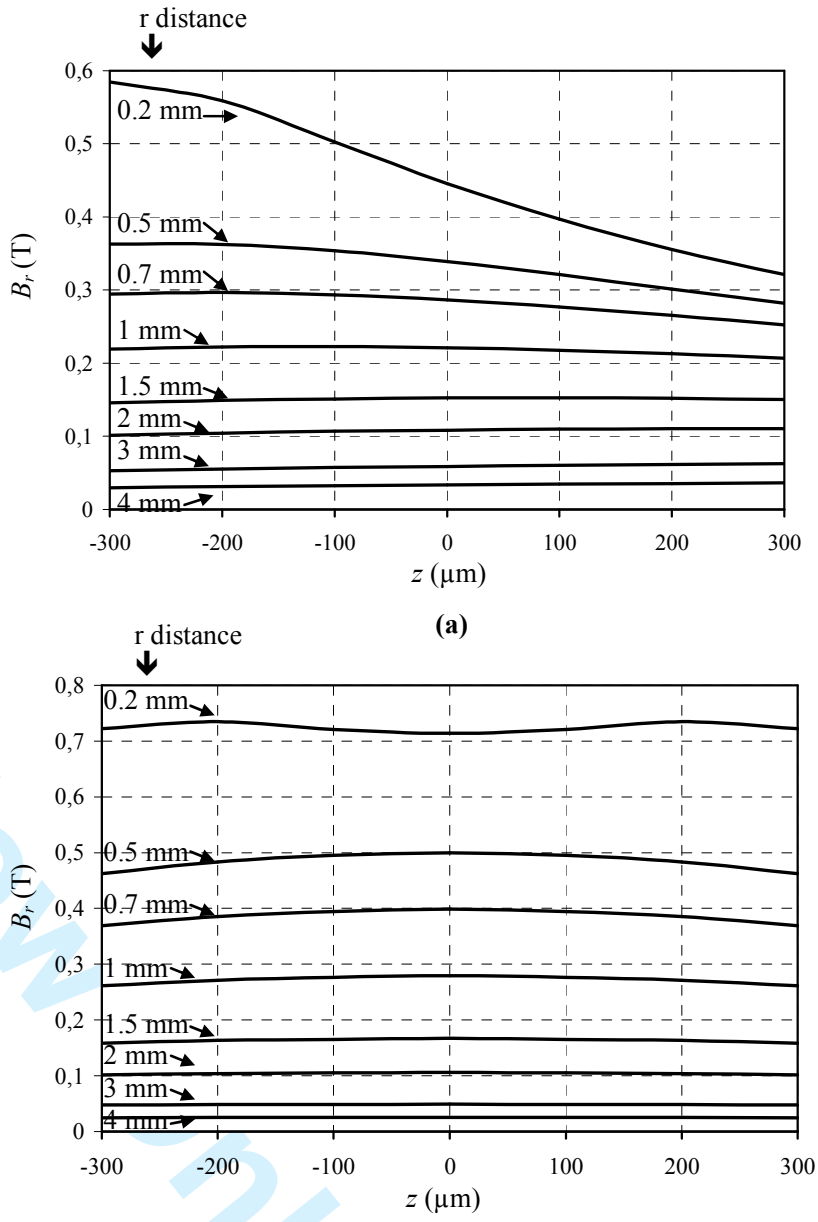

(b)

Figure 4) Radial component of magnetic flux density $B_{r}$ vs. vertical displacement $z$ for different radial $r$ distances from the magnets: (a) one ring magnet, (b) two ring magnets

\section{PlanAR COIL DESIGN}

This section exposes optimization principle of the microcoil for the sake of maximizing the electroacoustic efficiency. As mentioned before, the microcoil design is a key issue to set the microspeaker efficiency and its SPL as high as possible. Assuming that the most of the electrical power provided to the microspeaker is dissipated by Joule effect in the coil resistance $R$, the microspeaker electroacoustic efficiency $\eta$ for a membrane in piston-like movement can be calculated by (2) [26]: 


$$
\eta=\frac{\rho \cdot \pi \cdot a^{4}}{2 c} \cdot \frac{1}{R} \cdot\left(\frac{F_{f}}{M_{\text {coil }}+M_{\text {membrane }}}\right)^{2}
$$

In this equation, $\rho$ is the air density $\left(1.2 \mathrm{~kg} / \mathrm{m}^{3}\right.$ at $\left.20^{\circ} \mathrm{C}\right), a$ the membrane radius, $c$ the sound speed $\left(343 \mathrm{~m} / \mathrm{s}\right.$ at $\left.20^{\circ} \mathrm{C}\right)$, $M_{\text {coil }}$ and $M_{\text {membrane }}$ respectively the mass of the voice coil and the silicon membrane, $F_{f}$ the force factor of the electromagnetic motor.

Though MEMS technologies lead us to conceive preferably a planar coil, its geometric parameters still yield a system with high degree of freedom to optimize the efficiency. As Fig. 5 illustrates, among total seven independent parameters which influence the microspeaker efficiency, four parameters are related to the coil design: electric resistance, thickness, width, and inter-space of the coil turns (Fig. 6). The fifth and the sixth parameters concern the membrane radius and mass, and the seventh parameter is the radial component of the magnetic flux density created by the magnets.

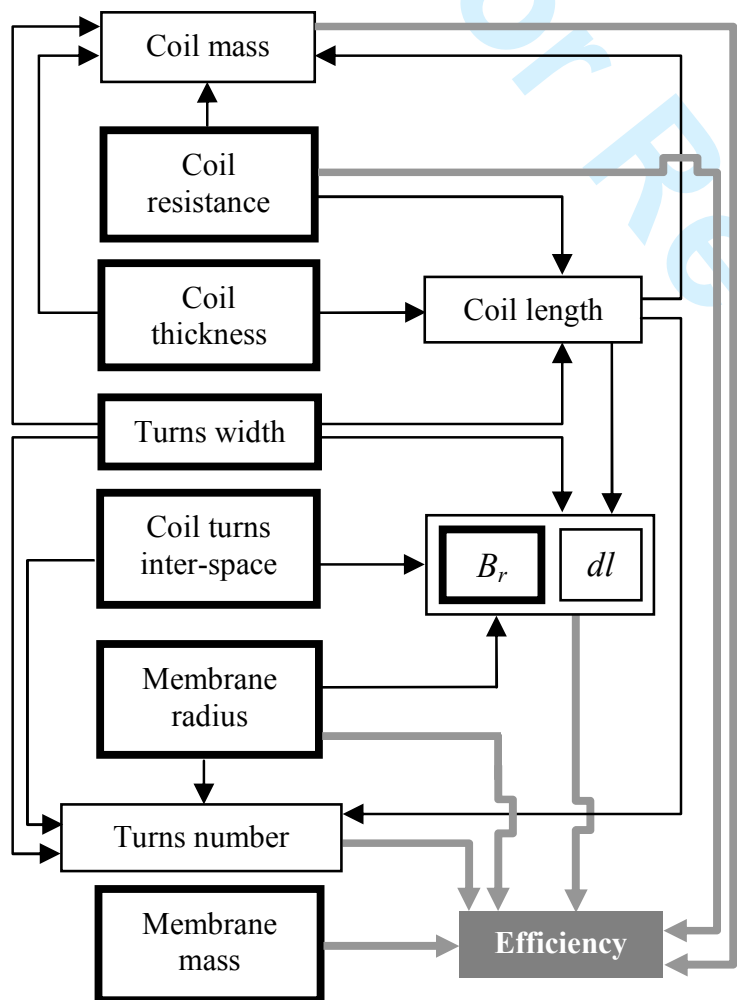

Figure 5) Flowchart of the microspeaker electroacoustic efficiency and influence of the seven independent parameters in bold blocks

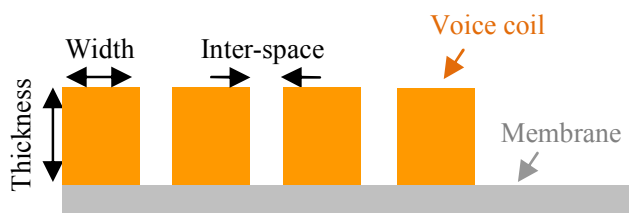

Figure 6) Schematic cut view of a the planar voice coil with its geometrical parameters

In order to obtain realistic values in this system, numerous technological constraints in terms of microfabrication and electroacoustic design were taken into account. Indeed, the coil resistance was set at $10 \Omega$ to be compatible with the associated amplifier electronic circuit. To meet the objective of $80 \mathrm{~dB}$ SPL in $10 \mathrm{~cm}$ beginning from $300 \mathrm{~Hz}$, and to supply a piston like motion in the microspeaker bandwidth, the membrane radius was set at $7.5 \mathrm{~mm}$ and its mass at $25 \mathrm{mg}$ [8]. Besides, the MEMS fabrication process used for electroplating the copper microcoil imposes dimensional limits on the microcoil thickness and turns inter-space. Actually, because of the photolithography resist used in micromolding step, the maximum achievable thickness for the microcoil was $30 \mu \mathrm{m}$ with minimum inter-space of $20 \mu \mathrm{m}$. Therefore, the only parameters that remain undefined are the coil turns width and the radial component of the magnetic flux density, calculated according to each magnetic structure. For both magnet configurations of Fig. 2, Fig. 7 depicts the variation of the $B_{r}$ parameter as a function of the distance from the magnets for null $z$ displacement. This is indeed the position mostly taken by the membrane, especially in medium and high working frequencies for which the displacement amplitudes remains below few microns. Therefore, for the rest of calculations these values of $B_{r}$ were taken into account. As simulation results stand, variations in $B_{r}$ with or without the presence of the copper microcoil are negligible, even for injected current as high as $1 \mathrm{~A}$.

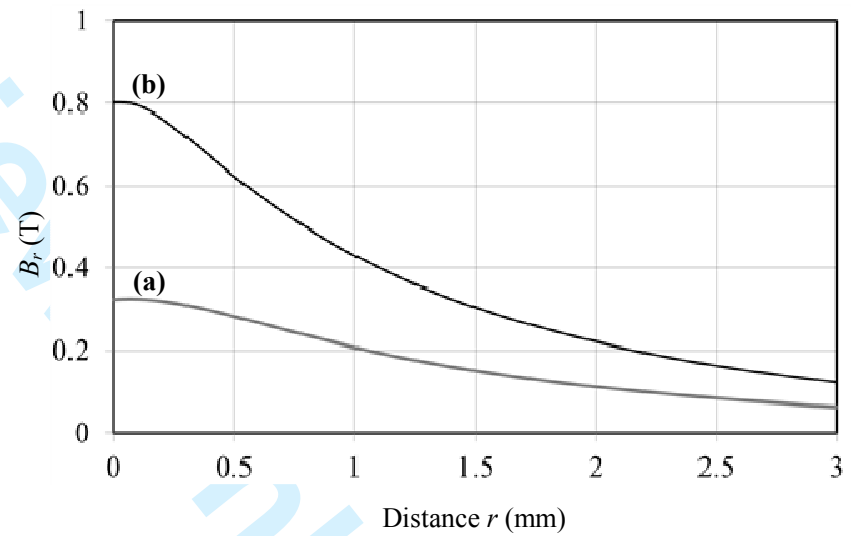

Figure 7) Radial component of magnetic flux density $B_{r}$ as a function of the distance $r$ for themicrocoil in rest position: (a) one magnet (Fig. 2-a), (b) two magnets (Fig. 2-b)

To increase the force factor as much as possible, the microcoil should be very long and ideally concentrated where the magnetic field is maximal. However, according to (2), the microcoil mass has a counterproductive effect on the efficiency. Therefore, to find the optimum coil mass, the only one undefined coil parameter, the turns width, was varied. As shown in Fig. 8, for the configuration of two magnets, the maximum efficiency of $0.008 \%$, takes place for a coil width of $35 \mu \mathrm{m}$. This sets a good trade-off between the force factor and the coil mass for the maximum efficiency. In respect of the coil electric resistance and microfabrication constraints previously mentioned, the optimized copper microcoil should have 14 turns and $5.8 \mathrm{mg}$ mass. 


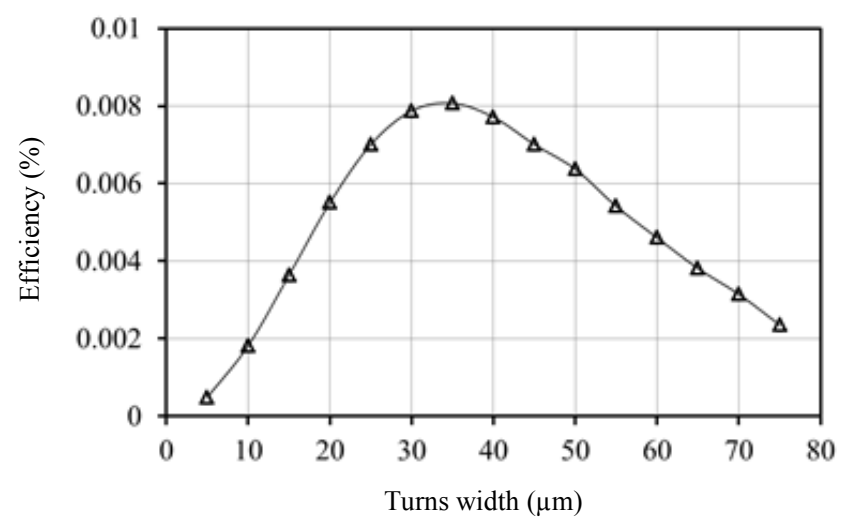

Figure 8) Microspeaker efficiency as a function of coil turns width for tworing magnet configuration, considering a coil resistance of $10 \Omega$, of $30 \mu \mathrm{m}$ turns thickness and $20 \mu \mathrm{m}$ inter-space

By the same method, the microcoil was optimized for the one ring magnet configuration. This resulted in 16-turn coil with $40 \mu \mathrm{m}$ turns width and a mass of $7.6 \mathrm{mg}$ yielding the maximum efficiency of $0.004 \%$.

\section{CHARACTERIZATION}

After setting the voice coil dimensions for the configuration of two magnets, the microspeaker fabrication was carried out in clean room. Then, as Fig. 9 shows, the device and two $\mathrm{NdFeB}$ ring magnets of $1.5 \mathrm{~T}$ were assembled together with the help of a transparent plexiglas frame. After making two external contact points with the electroplated copper coil, the device was installed on a test bench to measure in static mode the membrane out-of-plane displacement as a function of the injected current. For this purpose, Keyence LKG5000 laser displacement sensor was used.

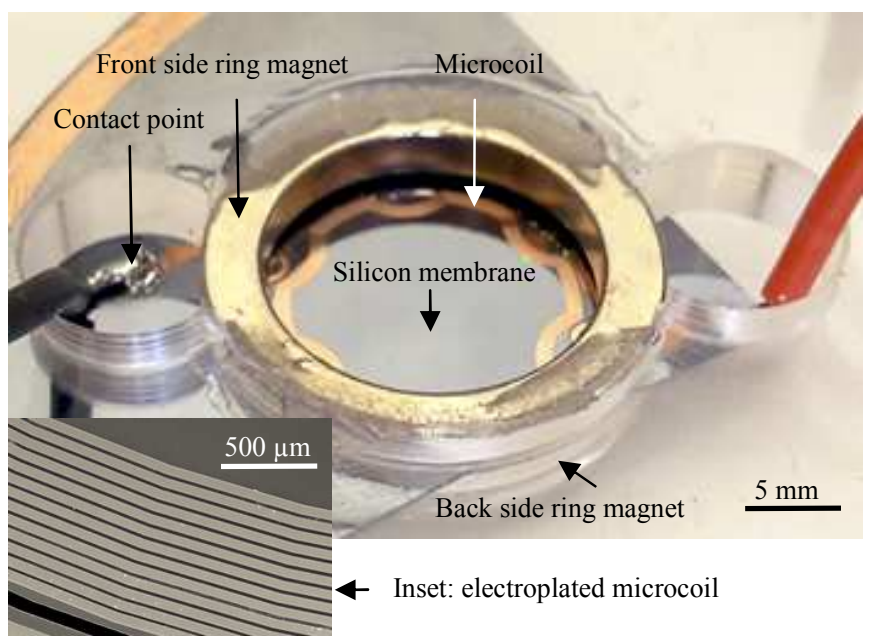

Figure 9) Micromachined silicon MEMS microspeaker assembled with two front and backside ring magnets

Photos of the membrane displacement for one magnet configuration are presented in Fig. 10-a and Fig. 10-b without and with injected electric current respectively.

Fig. 11 shows the measured membrane displacement as a function of the injected electric current for a device with either one or two ring magnets. These measurements cover the microspeaker peak-to-peak displacement, from $-300 \mu \mathrm{m}$ up to $+300 \mu \mathrm{m}$.

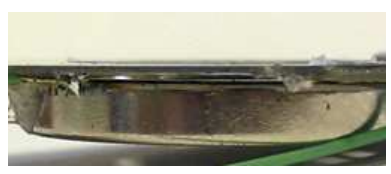

(a)

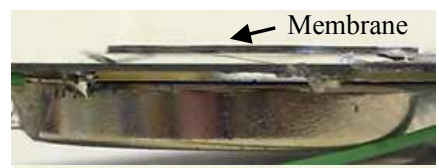

(b)

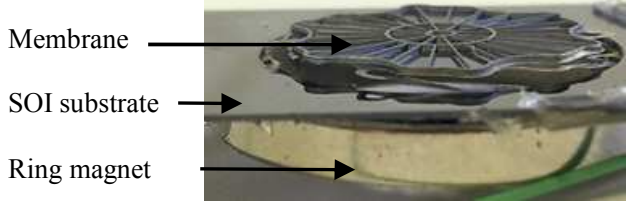

Figure 10) Membrane static displacement for one magnet configuration: (a) membrane in rest position, (b) displacement for $20 \mathrm{~mA}$ injected current

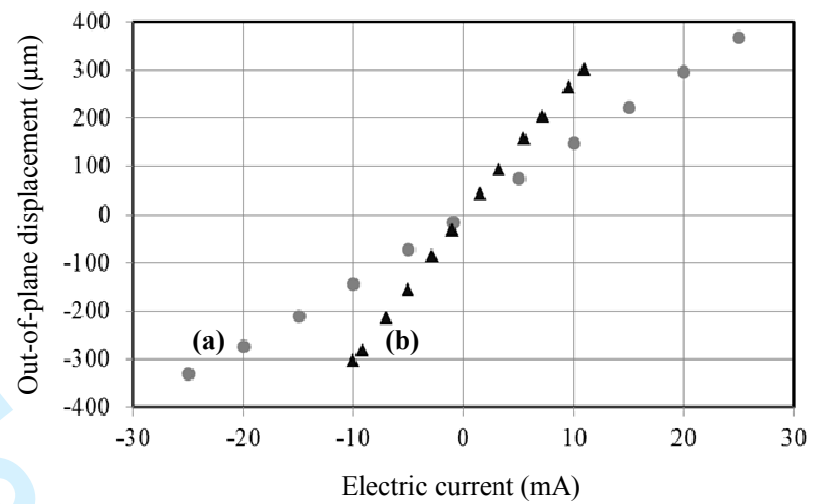

Figure 11) Measured membrane out-of-plane displacement as a function of the applied electric current: (a) with configuration of Fig. 2-a, (b) with configuration of Fig. 2-b

To determine the force factor, the mechanical model of the loudspeaker was taken into account. The vibration of the microspeaker membrane follows a second-order system, which can be described as [27][27]:

$$
M \frac{d^{2} z}{d t^{2}}+R \frac{d z}{d t}+k z=F_{z}
$$

Where $M$ is the mass of the mobile part, $R$ the mechanical resistance, $k$ the stiffness of the suspension springs, $z$ the membrane displacement, and $F_{z}$ the applied force defined also by the product of the force factor and the injected current.

In static mode, the only term that compensates the applied force is the suspension springs restoring force (Hooke's law). Therefore, knowing the injected current and the membrane displacement, the force factor can be calculated for each membrane position after measuring the springs stiffness. To do so, Futek CSG110 force sensor was used to establish the springs force-displacement diagram. As Fig. 12 shows, the suspension springs behave very linearly even for displacements bigger than $400 \mu \mathrm{m}$. So the suspension stiffness $k$ can be considered constant within the displacement range of interest, and equivalent to $7.0 \mathrm{~N} / \mathrm{m}$. 


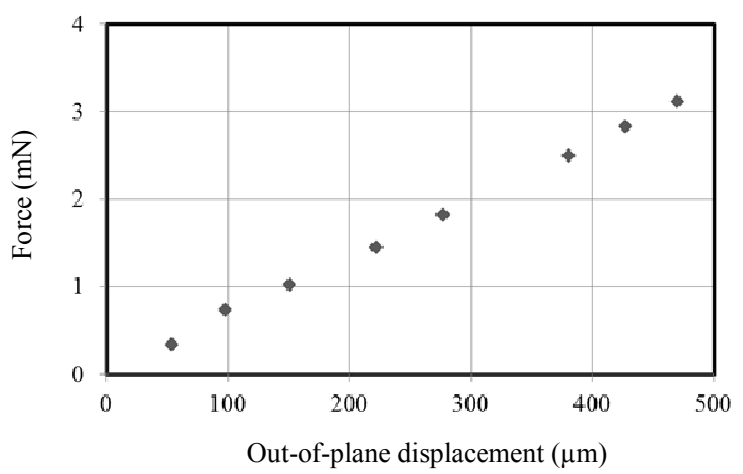

Figure 12) Measured mechanical force as a function of applied membrane displacement in static mode

The force factor was consequently calculated for each membrane position. The results for one-ring and two-ring magnets are presented in Fig. 13. In the same figure, the force factors calculated by the coupled FEM and analytical model are presented for each magnet configuration. For this purpose, the actual electroplated microcoil dimensions as well as the turns relative position to the magnets were taken into account for FEM simulations. The calculations also consider the actual geometrical shape of the microcoil, which was designed to increase the lifetime of the device. Indeed, the microcoil was shaped in a manner to evade as much as possible the mechanical stress in the membrane-suspension spring clamped zone.

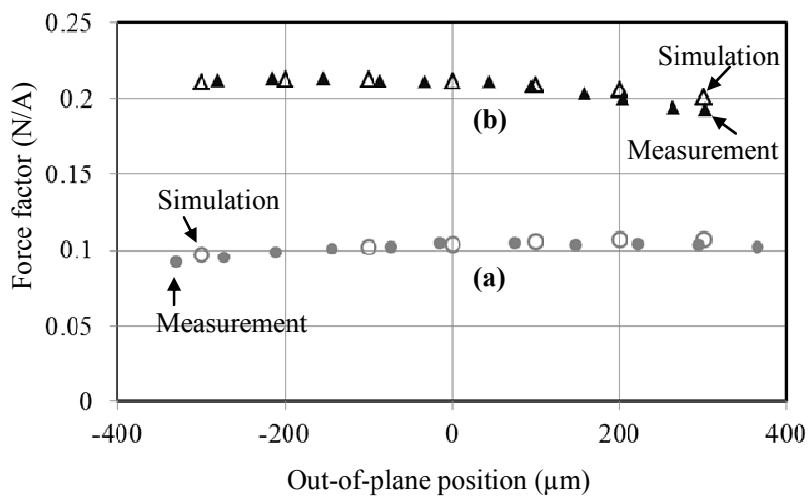

Figure 13) Force factor as a function of the membrane out-of-plane position: (a) one magnet with axial magnetization (Fig. 2-a), (b) two magnets with axial magnetization (Fig. 2-b)

Comparing the force factor values for each magnetic structure shows very good correlation between the expected simulation results and the experimental measurements. The one-ring and two-ring magnet configurations yield a force factor near to $0.1 \mathrm{~N} / \mathrm{A}$ and $0.2 \mathrm{~N} / \mathrm{A}$ respectively when the microcoil is positioned within $\pm 300 \mu \mathrm{m}$ displacement range (Fig. 13). It should be noted that for both magnet configurations, the resulted force factor is not completely symmetric for upward and downward displacements. This is due to the existence of an asymmetrical magnetic field distribution. Neither one topside magnet nor paired magnets in nonsymmetrical position to the microcoil rest position provides the same $B_{r}$ for symmetrical displacements of the microcoil.

In addition, comparing the resulted force factor of two-ring magnet configuration with that of the one-ring magnet, the force factor is raised by a factor of 2 . Consequently, according to (2), the microspeaker efficiency can be raised by a factor of 4.

The influence of other magnetic structures on the force factor was also studied: first, the two-ring magnet configuration with axial magnetization of $1.5 \mathrm{~T}$ and with an inner and an outer diameters of 15 and $21 \mathrm{~mm}$ respectively, second the same geometry of magnets, but with radial magnetization of $1.5 \mathrm{~T}$ instead of axial. Finally, configuration with only one ring magnet with radial magnetization of $1.5 \mathrm{~T}$ in front side of the device was examined. For each of these three configurations, the microcoil turns width was optimized, taking into account the same technological constraints.

As simulations results predict, by deploying one or two magnets with radial magnetization field, the force factor is almost halved comparing to the configuration of two-ring magnets with axial magnetization (Fig. 14-a vs. Fig 14-b and Fig. 14-c). On the contrary, by decreasing coil-magnet distance, magnets inner diameter of 15 instead of $16 \mathrm{~mm}$, the force factor rises from 0.2 to 0.35 N/A (Fig. 13-b vs. Fig 14a), which leads to a gain factor of 3 in efficiency. In other words, the efficiency can reach $0.024 \%$, which is more than two times higher than that of conventional microspeakers.

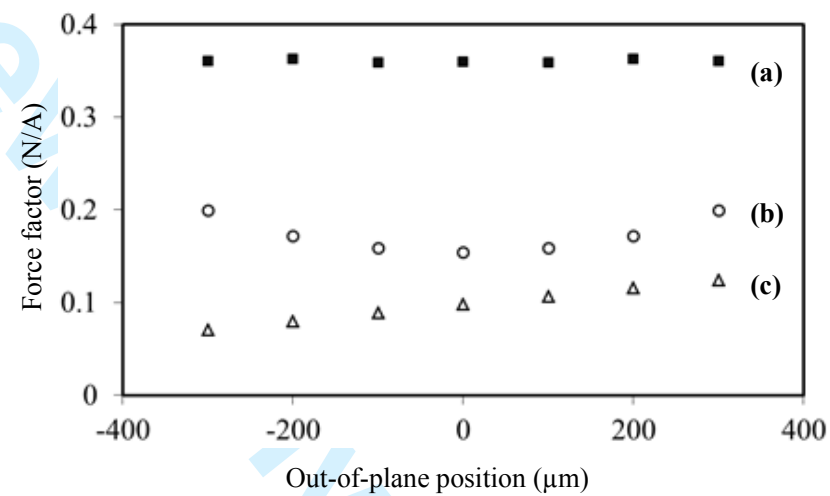

Figure 14) Simulated force factors as a function of the microcoil out-of-plane position: (a) two-ring magnets with axial magnetization, (b) two-ring magnets with radial magnetization, (c) one-ring magnet with radial magnetization

\section{CONCLUSION}

This work presented in the first place the structure of an electrodynamic microspeaker based on silicon material, able to be micromachined with the help of MEMS technology. As the electroacoustic efficiency of the microspeaker has a significant effect on the autonomy and the playback time of common mobile electronic devices, a special attention was paid to optimize the microspeaker electromagnetic motor.

For this purpose, a novel method was proposed to optimize the planar coil dimensions. It relies on one hand on FEM simulations to calculate the magnetic flux density created by permanent magnets within the voice coil distance, and on the 
other hand it uses analytical electro-mechano-acoustic models. It was shown on a flowchart that the microspeaker efficiency depends on the seven independent parameters. Among those, one parameter is related to the magnetic structure, two parameters to the microspeaker emissive surface, and four parameters to the voice coil.

The technological constraints related to the electronic amplifier, the acoustic power emission, and the microfabrication process were taken into account. This determined the membrane radius and mass, as well as the coil resistance, the coil turns thickness, and the turns inter-space. The spatial distribution of the magnetic flux density was set by the chosen permanent magnet configuration. Then, the coil turns width was varied in order to maximize the efficiency.

After carrying out the device microfabrication steps, the microspeaker force factor was experimentally determined for different out-of-plane positions of the microcoil. The results showed very good correlation between theoretical predictions and experimental results. This permitted to validate the proposed modeling technique, and investigate in further studies other magnetic structures with the objective of improving the electroacoustic efficiency. Among the different permanent magnet structures considered, the configuration of two ring magnets with axial magnetization promises more than 2 times higher conversion efficiency for the proposed electroacoustic transducer comparing to the best conventional microspeakers currently used in mobile phones.

\section{ACKNOWLEDGMENT}

This work has been financially supported by the French National Research Agency (ANR).

\section{REFERENCES}

[1] K. Lee, Y. Cho, and N. Chang, "High-level power management of audio power amplifiers for portable multimedia applications", in Proc. IEEE/ACM/IFIP Workshop on Embedded Sys. for Real Time Multimedia (2006), pp. 41-46.

[2] E. Sturtzer, G. Pillonnet, N. Abouchi, and F. Goutti, "System Approach to Avoid Audio Amplifier Oversizing in Mobile Phone Application", in Proc. Audio Engin. Soc. Conf. (2011).

[3] W. H. Groeneweg, "Analog signal processing for a class D audio amplifier in 65 nm CMOS technology", in Proc. Solid-State Circ. (2008) pp. 322-325.

[4] C. W. Lin, B. S. Hsieh, and Y. C. Lin, "Enhanced design of filterless class-D audio amplifier", in Proc. Design, Automation \& Test in Europe Conference \& Exhibition (2009) pp. 1397-1402.

[5] S. M. Hwang, H. J. Lee, K. S. Hong, B. S. Kang, and G. Y. Hwang, "New development of combined permanent-magnet type microspeakers used for cellular phones", IEEE Trans. on Magn. (2005) vol. 41, no. 5, pp. 2000-2003

[6] M.R. Bai, Y. L. Ching, and L. C. Rong, "Optimization of microspeaker diaphragm pattern using combined finite element-lumped parameter models" IEEE Trans. on Magn.(2008) vol.44, no.8, pp. 2049-2057.

[7] W. Kim, G. W. Jang, and Y. Y. Kim, "Microspeaker diaphragm optimization for widening the operating frequency band and increasing sound pressure level", IEEE Trans. on Magn. (2010) vol. 46, no. 1, pp. 59-66.

[8] I. Shahosseini, E. Lefeuvre, E. Martincic, M. Woytasik, J. Moulin, S. Megherbi, R. Ravaud, and Guy Lemarquand, "Microstructured silicon membrane with soft suspension beams for a high performance MEMS microspeaker", Microsyst. Technol. (2012) DOI 10.1007/s00542-012$1477-1$.

[9] F. L. Ayatollahi and B. Y. Majlis, "Design and Modeling of Micromachined Condenser MEMS Loudspeaker using Permanent
Magnet Neodymium-Iron-Boron (Nd-Fe-B)", in Proc. ICSE (2006) pp. $160-166$.

[10] M. C. Cheng, W. S. Huang, and S. R. S. Huang, "A Silicon Microspeaker for Hearing Instruments" J. Micromech. Microeng. 14 (2004) pp. 859-866.

[11] T. Lin, T. Meydan, and R. Rashedin, "Design method of microactuator with magnetic alloy iron-based amorphous plates for loudspeaker", IEEE Trans. on Magn. (2007) vol. 43, no. 6, pp. 2707-2709.

[12] F. Neri, F. Di Fazio, R. Crescenzi, and M. Balucani, "A Novel Micromachined Loudspeaker Topology", in Proc. Electronic Components and Technology (2011) pp. 1221-1227.

[13] K. S. Kim, J. H. Kwon, S. M. Hwang, and G. Y. Hwang, "Performance comparison of various magnetic circuits of integrated microspeakers and dynamic receivers used for mobile phones", J. Appl. Phys. (2008) 103.

[14] C. M. Lee, J. H. Kwon, K. S. Kim, J. H. Park, and S. M. Hwang, "Design and analysis of microspeaker to improve sound characterizatics in a low frequency range", IEEE Trans. on Magn. (2010) vol. 46, no. 6.

[15] G. Y. Hwang, H. J. Lee, S. M. Hwang, B. S. Kang, and S. K. Jeung, "Performance comparison between inner and outer permanent magnet type microspeakers used for mobile phones", J. Appl. Phys. (2003) vol. 93, no. 10 , pp. 8519-8521.

[16] G. Lemarquand, R. Ravaud, I. Shahosseini, V. Lemarquand, J. Moulin, and E. Lefeuvre, "MEMS electrodynamic loudspeakers for mobile phones", Appl. Acoustics (2012) vol. 73, no. 4, pp. 379-385.

[17] Y. C. Chen, Wei-Ting Liu, Tzu-Yuan Chao, and Y. T. Cheng, "An optimized cu-ni nanocomposite coil for low-power electromagnetic microspeaker fabrication", in Proc. IEEE Transducers (2009) pp. 25-28.

[18] S. S. Je, F. Rivas, R. E. Diaz, J. Kwon, J. Kim, B. Bakkaloglu, S. Kiaei, and J. Chae, "A compact and low-cost MEMS loudspeaker for digital hearing aids", in Proc. IEEE Transactions on Biomedical Circuits and Systems (2009) vol. 3, no. 5, pp. 348-358.

[19] B. Merit, G. Lemarquand, and V. Lemarquand, "Performances and design of ironless loudspeaker motor structures", Appl Acoust (2010) doi:10.1016/j.apacoust.2009.12.004.

[20] I. Shahosseini, E. Lefeuvre, M. Woytasik, J. Moulin, X. Leroux, S. Edmond, E. Dufour-Gergam, A. Bosseboeuf, G. Lemarquand, and V. Lemarquand, "Towards High Fidelity High Efficiency MEMS Microspeakers" in Proc. IEEE Sensors (2010) pp. 2426-2430.

[21] Y. Chida, H. Katsumata, T. Fujiya, S. Kaihatsu, T. Morita, D. Hoshino, and Y. Nishioka, "Silicon linear actuator driven by electrochemomechanical strain of polypyrrole film", Sens. and Actu. (2011) 169, pp. 367-37.

[22] M. Legros, O. Ferry, F. Houdellier, A. Jacques, and A. George, "Fatigue of single crystalline silicon: Mechanical behaviour and TEM observations", Mat. Sci. and Engin. (2008) 483, pp. 353-364.

[23] T. D. Rossing, "Handbook of Acoustics, Springer", 2007, ISBN 978-0387-30446-5.

[24] I. Shahosseini, E. Lefeuvre, J. Moulin, E. Martincic, M. Woytasik, B. Belier, G. Lemarquand, "Silicon-based MEMS microspeaker with large stroke electromagnetic actuation", in Proc DTIP (2012) pp. 8-12.

[25] Y. C. Chen and Y. T. Cheng, "A low-power milliwatt electromagnetic microspeaker using a PDMS membrane for hearing aids application", in Proc. IEEE MEMS (2011) pp. 1213-1216.

[26] A. D. Pierce, Acoustics, Acoustical Society of America, ISBN 0-88318612-8, 1989.

[27] W. T. Thomson and M. D. Dahleh, "Theory of Vibration with Applications" Englewood Cliffs, NJ: Prentice-Hall (1998). 